\title{
Spiral organisms in endoscopic biopsies of the human stomach
}

\author{
TP ROLLASON, J STONE, JM RHODES \\ From the General Hospital and Selly Oak Hospital, Birmingham
}

SUMMARY A retrospective light microscopic study of 310 consecutive endoscopic gastric biopsy specimens was performed. Spiral bacteria were found in $42 \%$ of cases and, apart from occasional organisms in parietal cell canaliculi, were confined to the surface of the glands and epithelium. Electron microscopic study of selected cases showed the bacteria to be approximately $6 \mu \mathrm{m}$ maximum length and $0.7 \mu \mathrm{m}$ diameter with a spiral periodicity of $1.2 \mu \mathrm{m}$. A significant association between the occurrence of spiral bacteria and gastritis was noted but not with carcinoma, peptic ulceration, or high $\mathrm{pH}$ of the gastric aspirate.

Recent years have witnessed considerable interest in spirochaetosis in the large intestine of man and throughout the intestine in animals. ${ }^{1}$ Considerable discussion has centred around the role of large intestinal spirochaetes in disease in $\operatorname{man}^{2-4}$ but no consensus has emerged. It is perhaps not generally realised that spiral organisms were described in the stomach of both man and domestic animals a considerable time $\mathrm{ago}^{56}$ and a role postulated for them in the causation of gastric carcinoma and nonneoplastic ulceration. These studies were, however, performed prior to the advent of fibreoptic endoscopy and usually carried out on postmortem material. We felt therefore that it would be interesting to assess retrospectively the prevalence of spiral bacteria in the stomach in human endoscopic biopsy specimens and examine its relative incidence in various disease states.

\section{Material and methods}

All biopsy samples of the stomach removed at fibreoptic endoscopy in one year at a large General Hospital were examined retrospectively by light microscopy. Selected examples were reprocessed for electron microscopy and a small prospective study (12 cases) was performed to attempt to culture the organisms and obtain fresh tissue for electron microscopic study.

\section{LIGHT MICROSCOPY}

Biopsied tissue was fixed in neutral buffered formalin and routinely processed. Sections were cut at 5

Accepted for publication 15 September 1983 $\mu \mathrm{m}$, stained with haematoxylin and eosin and viewed under oil immersion ( $\times 100$ objective). As has been noted elsewhere ${ }^{6}$ spiral bacteria in the stomach are readily visible using this simple method, this would also appear to be the case for large intestinal spirochaetes. ${ }^{3}$ In occasional cases where considerable doubt existed the Warthin-Starry method for spirochaetes ${ }^{7}$ was performed on the paraffin sections; this stained the organisms intensely.

The site of the gastric biopsy-that is, cardia, body or antrum was assessed using the criteria set out by Whitehead. ${ }^{8}$ Many cases were difficult to classify by site but all were assigned to the most likely site except carcinomas and gastric ulcers. This may overestimate the number of pyloric biopsies somewhat due to the presence of pseudopyloric metaplasia. Those, surprisingly few, biopsy tissues where the fragments were from more than one area were classified according to the majority of the biopsy tissue rather than assigned to two or more categories which would have caused problems of duplication. Any case where the whole of one biopsy fragment was ulcer material was classified as peptic ulcer. Any case where malignant cells were present in any fragment was classified as carcinoma.

Assessment of the presence or absence of gastritis was performed using the criteria laid out by the same author stated above. ${ }^{8}$ These cases were subdivided into superficial gastritis and atrophic gastritis/gastric atrophy.

TRANSMISSION ELECTRON MICROSCOPY

Fresh tissue was fixed in $2.5 \%$ glutaraldehyde in $\mathbf{0 . 1}$ $\mathrm{M}$ cacodylate buffer, $\mathrm{pH} 7 \cdot 3$, for two hours, washed 
in cacodylate buffer and post-fixed in $1 \%$ osmium tetroxide. After dehydration the tissue was embedded in Araldite resin and ultrathin sections cut. The grids were stained with uranyl acetate and lead citrate and viewed in a Jeol $100 \mathrm{~S}$ electron microscope at $80 \mathrm{kV}$. Tissue was also reprocessed for electron microscopy from paraffin embedded material which was dewaxed, rehydrated, post-fixed in $1 \%$ osmium tetroxide and then treated as above.

\section{CULTURE METHOD}

Biopsy specimens from 10 consecutive patients being endoscoped for upper gastrointestinal tract symptoms were immediately placed in anaerobic transport medium. Repeat samples were taken for light microscopy from each case. The tissues were cultured in fastidious anaerobic broth with added calf serum in an anaerobic cabinet for three weeks with regular examinations by dark ground microscopy.

\section{Results}

\section{MICROSCOPY}

On light microscopy $42.6 \%$ of the 310 specimens examined contained spiral bacteria. The spiral organisms were visible in haematoxylin and eosin stained sections as faint slightly haematoxyphil curved structures present on the surface of the superficial gastric mucosa but seen more readily in the necks and bases of gastric glands where they were often extremely numerous (Fig. 1). The bacteria were faintly Gram-negative and did not stain well with the Giemsa stain. No infiltration of glandular or surface epithelial cells or the lamina propria

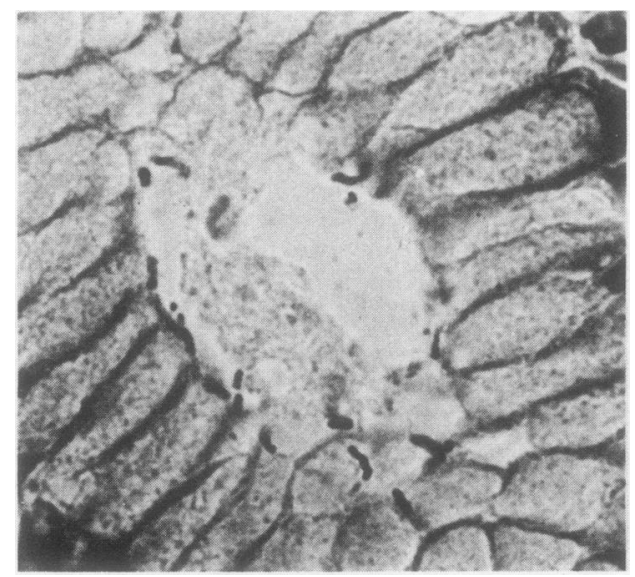

Fig. 1 A number of spiral organisms are present on the luminal surface of the gastric gland. Warthin-Starry silver stain. $\times 640$ (approx).

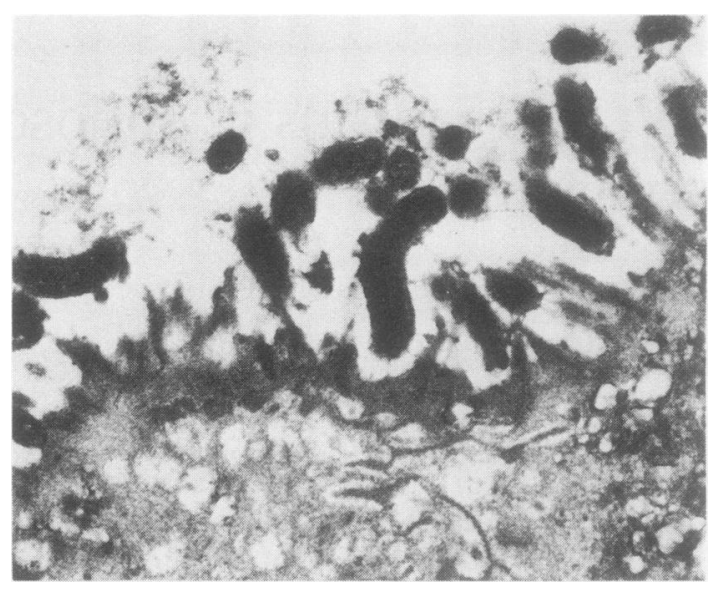

Fig. 2 Spiral organisms with a clearly defined cell membrane are seen on the luminal surface of the gastric glandular epithelial cell. Electron micrograph from material reprocessed from paraffin block. $\times 10800$.

was identified on light microscopic examination. Electron microscopy (Figs. 2-4) revealed a structurally homogeneous population of organisms measuring approximately $0.7 \mu \mathrm{m}$ diameter. The maximum observed length was approximately $6 \mu \mathrm{m}$. No axial filaments were identified. A clearly defined cell wall was present but flagellae were not seen. The periodicity of the spiral was $1.2 \mu \mathrm{m}$. By electron microscopy occasional spiral bacteria were present within parietal cell canaliculi.

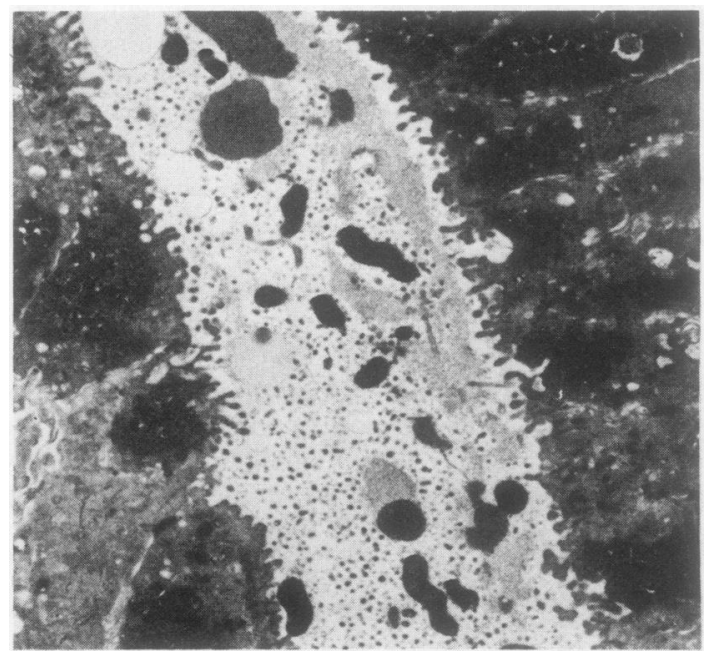

Fig. 3 Spiral organisms are present within the glandular lumen with no obvious orientation in relation to epithelial cells. Electron micrograph. $\times 4200$. 


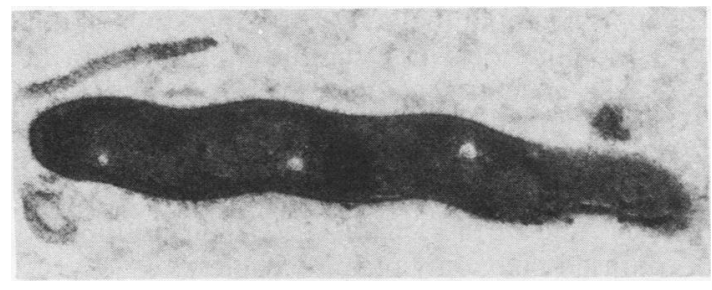

Fig. 4 A spiral organism is seen lying free on the luminal surface of a gastric glandular epithelial cell. Fine fibrillary processes can be seen on the outer capsular surface of the cell. Electron micrograph. $\times 17000$.

\section{CULTURE}

No growth of the organisms was obtained at any point despite the fact that biopsies from six of the 10 specimens cultured contained numerous spiral bacteria.

\section{RELATIONSHIP OF THE PRESENCE OF SPIRAL BACTERIA TO OTHER FACTORS}

Of the 310 biopsies $58 \%$ were from men and $42 \%$ from women. There was no significant difference in the incidence of spiral bacteria in the two groups ( $41 \%$ for men and $44 \%$ for women). The age ranges of the biopsy cases with and without spiral bacteria are shown in the graph, again no significant difference was noted in the two groups (Fig. 5).

When grouped by site of biopsy (ulcer and carcinoma excluded) $9 \%$ of biopsies taken from the cardia were positive compared with $48 \%$ from the body and $54 \%$ from the pylorus. The cardia, however, accounted for only $9 \%$ of all biopsies (compared with $61 \%$ from the body and $30 \%$ from the pylorus) and the figures are not significantly different $(\mathrm{p}<0.1>0.05)$.

When incidence rates of spiral bacterial occurrence were compared in gastritis (all types together), carcinoma, peptic ulcer and normal stomach (Fig. 6) the incidence was significantly higher in gastritis cases when compared to the other groups $(p<0.01)$ $56 \%$ of gastritis cases being positive compared to $34 \%$ of peptic ulcers, $19 \%$ of carcinoma and $21 \%$ of normals. Differences in the other groups do not achieve statistical significance. This high incidence holds equally for both superficial gastritis and atrophic gastritis/gastric atrophy with no significant difference in these groups and is not dependent on biopsy site (cardia excluded).

A subjective assessment of numbers of spiral bacteria present was performed using a scale of 0 to +++ . Comparison of the numbers of spiral bacteria present by this method with severity and type of gastritis-that is, superficial gastritis or atrophic gastritis/gastric atrophy, revealed no significant difference in bacterial numbers in the two groups.

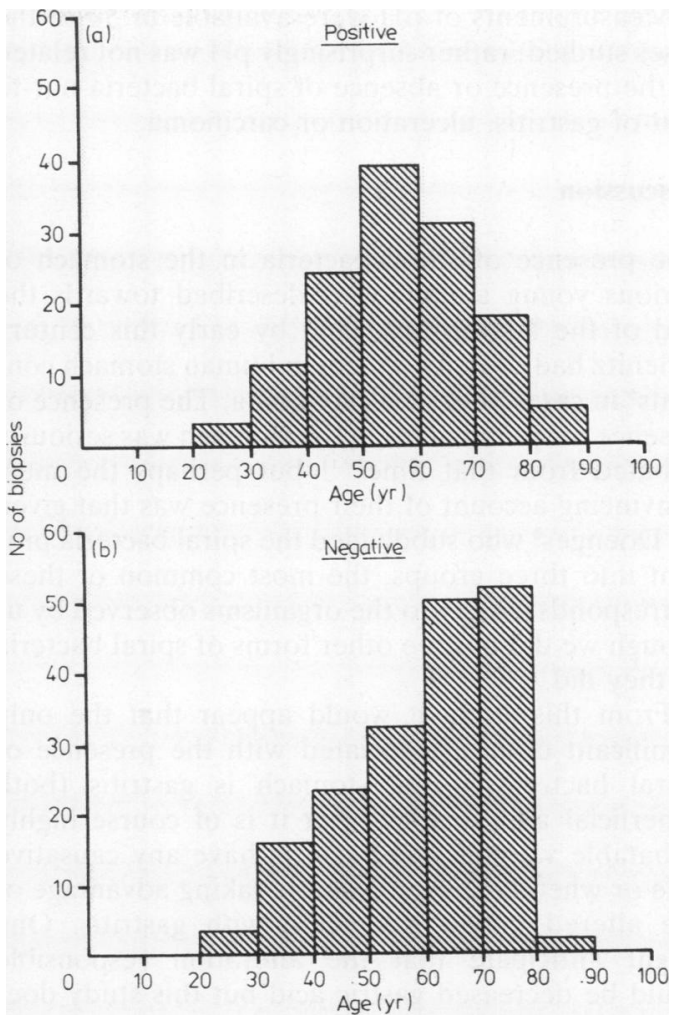

Fig. 5 Age distribution of biopsies with (positive) and without (negative) spiral organisms.

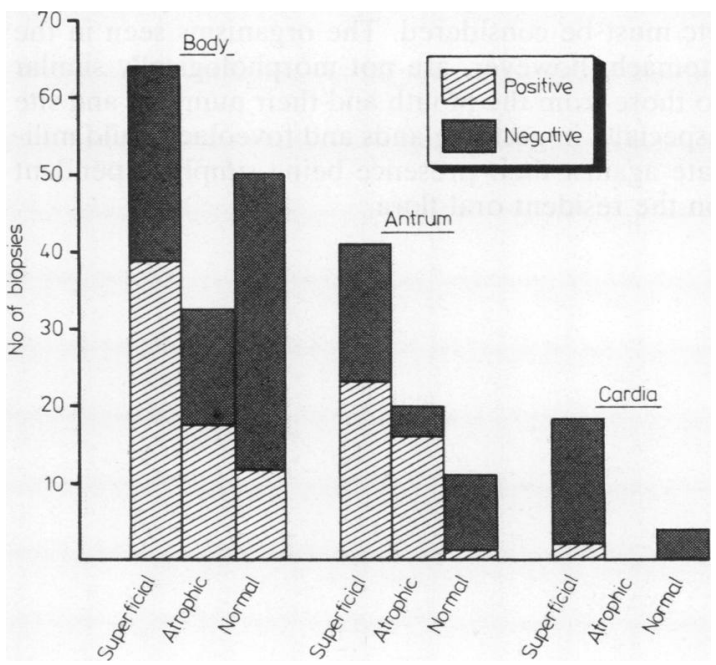

Fig. 6 Relative numbers of positive and negative biopsies in each gastric zone in gastritis and normal biopsies. 
Measurements of $\mathrm{pH}$ were available in $\mathbf{5 0}$ of the cases studied; rather surprisingly $\mathrm{pH}$ was not related to the presence or absence of spiral bacteria nor to that of gastritis, ulceration or carcinoma.

\section{Discussion}

The presence of spiral bacteria in the stomach of various young animals was described towards the end of the last century ${ }^{9}$ and by early this century Krienitz had described them in human stomach contents ${ }^{5}$ in cases of gastric carcinoma. The presence or absence of spirochaetes in the stomach was seriously debated from that time ${ }^{1011}$ but perhaps the most convincing account of their presence was that given by Doenges ${ }^{6}$ who subdivided the spiral bacteria present into three groups, the most common of these corresponds closely to the organisms observed by us though we did not see other forms of spiral bacteria as they did.

From this study it would appear that the only significant disease associated with the presence of spiral bacteria in the stomach is gastritis (both superficial and atrophic) but it is of course highly debatable whether the bacteria have any causative role or whether they are simply taking advantage of the altered milieu associated with gastritis. One might anticipate that the alteration responsible could be decreased gastric acid but this study does not support that contention. It may be that the spirochaetes are protected by the gastric mucous layer in most circumstances.

Spiral organisms are of course very numerous in the mouth and the possibility that those in the stomach are merely carried there in swallowed saliva etc must be considered. The organisms seen in the stomach, however, are not morphologically similar to those from the mouth and their numbers and site especially in gastric glands and foveolae would militate against their presence being simply dependent on the resident oral flora.
There is no doubt that a retrospective study of this type is not the ideal way to study the question of gastric spirochaetosis and the methods of division of the gastric mucosa by site and disease are fraught with practical difficulties. Nonetheless, this topic merits further study to determine the role of these organisms and further characterise their position in the confused taxonomy of spirochaetes.

We gratefully acknowledge the excellent technical assistance of the Histology Laboratory staff at the General Hospital, Birmingham and the secretarial assistance of Miss Angela Wright, Mrs Joyce Cheney and Mrs Phyllis Edwards.

\section{References}

${ }^{1}$ Drawer BS, Hudson MJ. Spiral organisms in intestinal disease. In: Reeves DS, Geddes AM, eds. Recent advances in infection. Vol 1. Edinburgh: Churchill-Livingstone, 1979:41.

${ }^{2}$ Douglas JG, Crucioli V. Spirochaetosis a remediable cause of diarrhoea and rectal bleeding. $\mathrm{Br}$ Med J 1981;283:1362.

${ }^{3}$ Lee FD, Kraszewski A, Gordon J, Howie JGR, McSeveney D, Harland WA. Intestinal spirochaetosis. Gut 1971;12:126.

4 Gad A, Willen R, Furugard K, Fors B, Hradsky M. Intestinal spirochaetes as a cause of longstanding diarrhoea. Ups J Med Sci 1977;82:49.

${ }^{5}$ Krienitz W. Ueber das Auftreten von Mageninhalt bei Carcinoma Ventriculi. Dtsch Med Wochenshr 1906;22:872.

- Doenges JL. Spirochaetes in the gastric glands of Macacus rhesus and of man without related disease. Arch Pathol 1939;27:469.

' Warthin AS, Starry AC. A more rapid and improved method of demonstrating spirochaetes in tissues. American Journal of Syphilis 1920;4:97.

${ }^{8}$ Whitehead R. Mucosal biopsy of the gastrointestinal tract. 2nd Ed. Philadelphia: WB Saunders, 1979: Chapters 1-5.

'Salomon H. Ueber das Verhalten des Saugetiermagens und sein Verhalten zu den. Belegzellen Centralbl F Bakt (Abt 1). 1896;19:433.

${ }^{10}$ Celler HL, Thalheimer W. Bacteriological and experimental studies on gastric ulcer. J Exp Med 1916;23:791.

"Freedburg AS, Barnon LE. The presence of spirochaetes in the human gastric mucosa. Am J Dig Dis 1940;7:443.

Requests for reprints to: Dr TP Rollason, Consultant Histopathologist, Department of Pathology, Maelor General Hospital, Wrexham LL13 7TD, Wales. 